\title{
Application with Internet of things technology in the municipal industrial wastewater treatment based on membrane bioreactor process
}

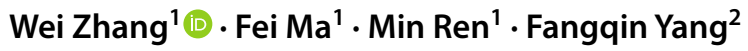

Received: 15 December 2020 / Accepted: 25 January 2021 / Published online: 22 February 2021

(C) The Author(s) 2021

\begin{abstract}
Anoxic-oxic process is also called anaerobic aerobic process and used widely with the membrane bioreactor (MBR) for wastewater treatment, particularly in China, thanks for their high efficiency, good-quality permeate and easy operation. However, because the content of the feed wastewater fluctuates in a large range and the operation condition of the system needs to be controlled accurately, it is very important to find an efficient way to constantly monitor the nodes of the system, and adjust the operation parameters, including the quantities used in the chemical treatment. Therefore, it is necessary to use Internet of things technology (IOT) sensing and control equipment to realize the dynamic monitoring of sewage treatment process parameters, so as to serve the drug delivery and equipment online control. This study introduces an application case based on IOT sensor control and supporting maintenance business. Through the practical application of this technology in an environmental protection sewage treatment enterprise in Wuxi, this study introduces a method of bringing the IOT into the MBR system of industrial wastewater treatment which can continuously and accurately monitoring the nodes of the system. Based on this study, an analysis and decision-making system based on real-time monitoring data can be realized to adjust operation parameters in time. In this method, the IOT is introduced into the MBR system of industrial wastewater treatment. The results show that with the support of IOT, the sewage treatment system runs stably and the treatment efficiency is significantly improved.
\end{abstract}

Keywords $\mathrm{AO}+\mathrm{MBR} \cdot$ Wastewater $\cdot$ Internet of things technology $\cdot$ Digital signal processor $\cdot$ Windows control center

\section{Background}

Rapid economic growth has caused tremendous damage to China's ecological environment, especially the hydrographic environment, which results in great pressure on emission reduction and pollution control.

In $\mathrm{AO}$ (anoxic-oxic) process, the 'A' (anaerobic) is the anaerobic section, which is used to remove nitrogen and phosphorus and the ' $\mathrm{O}$ ' (oxic) is the aerobic section, which is used to remove organic matter in wastewater. The

Wei Zhang

weizhang1211@foxmail.com

1 School of Electromechanical and Information Engineering, Wuxi Vocational Institute of Arts and Technology, Yixing 214206, China

2 Zhong Zhi Cheng Information Technology (Suzhou) Ltd, Shanghai 201704, China advantage from $\mathrm{AO}$ is that in addition to the degradation of organic pollutants, it also has a certain function of nitrogen and phosphorus removal. It is the pretreatment of activated sludge with anaerobic hydrolysis technology. Membrane bioreactor (MBR) is a classical wastewater treatment process (Meng et al. 2021) combining membrane technology with biological method for its solid-liquid separation efficiency is significantly higher than that of conventional activated sludge (CAS) process (Huang et al. 2010).

For the extensive use of $\mathrm{HF}$ and $\mathrm{HNO} 3$ acids during the silicon wafers production process (Belkada et al. 2018), the electrodialysis application to remove these ions is affected by several operational factors in the treatment performance such as current intensity, initial pollutants concentration and $\mathrm{pH}$ in minutes. A delay of the nitrate ions delivery in the solution will significantly affect the fluoride removal efficiency (Belkada et al. 2018) in the photovoltaic industry wastewater. Now the real-time monitoring data of ions concentration in water now can be sampled by different kinds 
of sensors and controllers deployed on the Internet of things platform. In fact, IOT facilities are widely used in wastewater treatment. A set of Internet of Things (IoT) applications was used on a 1000-pig farm to a smart wastewater treatment system which had a removal efficiency of biochemical oxygen (BOD), chemical oxygen (COD), and suspended solids (SS) to $93 \%, 89 \%$ and $97 \%$, and $94 \%, 86 \%$ and $96 \%$ (Su et al. 2020).

As a kind of wireless sensor networks using a promising technology for water quality monitoring and management, the use of wireless sensor on IOT networks facilities improves the current centralized systems and traditional manual methods, which makes the distributed intelligent water quality monitoring system adapt to the urban dynamic heterogeneous water distribution infrastructures (Martinez et al. 2020).

Just like in the Middle East and North Africa region, the use of wastewater is treated to an advancement by using IoT technologies and it can offer obvious benefits of freshwater without the problems of supply and cost (Rashid 2020). With these digital Internet of Things (IoT), well-designed systems may incorporate any or a combination of membrane bioreactor solutions supported by the right chemistry, delivered in the right quantity at the right spot under approach (Rashid 2020). And the Internet of Things (IoT) is an important technological innovation that can enhance industrial competitiveness and sustainability. In several districts, the applicability for promoting industrial sustainability of IoTs in smart manufacturing industry (including wastewater treatment) was verified by an empirical study (Kao et al. 2019). Further, as an important part of wastewater treatment plants, IOT can provide important on-line monitoring data for the preparation of facility maintenance plan which is known as an electrical preventive maintenance (EPM) programs and prevent unnecessary damage and/or replacement due to neglect (Malhotra et al. 2021).

With increasing effluent discharge standards, wastewater treatment plays a more important role in the social development (Wang et al. 2020). Multi-mode aerobic membrane bioreactor $(\mathrm{AO}+\mathrm{MBR})$ process has been applied in industrial wastewater treatment due to its merits such as high efficiency, good-quality permeate and easy operation (Al-Bayari et al. 2020).

Dedicated digital signal processor (DSP) is usually employed as control center of the wastewater treatment system. Windows control center (WinCC) platform connects the control nodes in the wastewater treatment process with IoT control equipment on the plant's dedicated network to achieve the best performance, and it can realize a kind of real-time control of the overall process. This mode has series of characters, which include low overall network latency, stable signal sampling, less communication traffic consumption, flexible adaptation to different working conditions, overall technology, and so on. Each equipment status based on WinCC platform is reliable, which presented excellent in dedicated control performance. The daily equipment maintenance and process status changes, mainly relying on manual, ledger and video inspection (Huang et al. 2010). While facing with city-level wastewater treatment system operation, maintenance management and water quality intelligent dynamic supervision business model, this model will face many deficiencies, such as complex liquid-phase working condition equipment working condition monitoring, environmental dynamic monitoring, manual daily inspection, the import and export of water quality monitoring, alarm valve, and so on. It is difficult to use the configuration platform as easy and convenient services such as pre-determining value strategies, predicting emergency situations and replacing assets in wearable equipment. Long-term robust operation of the wastewater treatment system at the city level also will bring predictable to the user. In this paper, a sewage treatment project in an economic development zone of Wuxi, China, was investigated as an example, the industrial wastewater treatment process based on $\mathrm{AO}+\mathrm{MBR}$ membrane technology was discussed, and the key technology for the construction of a city-level wastewater treatment based on IoT control system platform was analyzed (dos Santos et al. 2021).

The Integrated Circuit Materials Industrial Park of Wuxi is serving the large silicon chip production, which mainly produces chemical mechanical polishing materials, highpurity chemical reagents, electronic gases, photoresists, mask plates, compound semiconductor materials, advanced packaging materials, and so on. By 2025, the scale of integrated circuit (IC) material industry will exceed 30 billion Yuan, and the park will become the largest integrated circuit material industry cluster in East China. Meanwhile more and more key enterprises are gathering in the industrial park. According to expectations, there will gather more than 50 key integrated circuit material enterprises.

The wastewater treatment project discussed in this paper mainly serves the newly built large silicon chip and components supporting enterprises, and it is an independent supporting sewage treatment plant for the area and is also a necessary condition for the smooth operation of the large silicon industrial park. The daily processing capacity is 50,000 tons. The park consists of three areas, which are chemical industry area (electronic chemicals area, $5.5 \mathrm{~km}^{2}$ ), large silicon wafer supporting area (800 acres) and components supporting area (700 acres). According to the implementation plan of water environment comprehensive treatment in Taihu Lake Basin, the over allowable discharge of $\mathrm{COD}_{\mathrm{Cr}}$, ammonia nitrogen, total nitrogen and total phosphorus is reduced by $50 \%$ (2005 is the base year) from 2012. The water quality target of hemp section of the canal is lower than 2.0, reaching class 
V standard, total phosphorus reaching class IV and permanganate index reaching class III (Niaei et al. 2021).

\section{Current characteristics of municipal-scale industrial effluents}

1. More special equipment. Industrial wastewater treatment is an emerging sunrise industry, which has a broad application prospect. A variety of new sensors constantly spring up. This leads to poor interchangeability with the same type of equipment and a unified maintenance standard. At the same time, with rapid development of electronic technology, wastewater treatment equipment and intelligent IT components, it is difficult to purchase the fittings when the old equipment upgrades.

2. Wastewater treatment capacity increases rapidly. With the raising of urbanization quality, industrial urban sewage treatment plants are used more and more widely. It also needs more capacity and new types of wastewater treatment. With the addition of different types of industrial production lines in the city, different industrial wastewater treatment facilities will be built.

3. Wastewater component changes significantly. The urban industrial wastewater to be treated will change significantly with the changes of seasons and plant process. Changes in the evolution of the wastewater components occur, resulting in the need for simultaneous and timely adjustments to subsequent wastewater treatment processes. In addition, in different seasons and weather, urban storm water can also significantly increase the management of urban industrial wastewater treatment.

4. Wastewater operations have significant risk. Industrial wastewater, dissolving large quantities of biochemical harmful substances, will harm the wastewater treatment plant pond, grille, primary sedimentation tank, sedimentation tank and other facilities. The sludge treatment, sludge storage tank, dewatering machine room and other nodes will be accompanied by a large number of toxic and hazardous substances, which will not only endanger the site operators, but also affects the routine maintenance of equipment and the quality of wastewater disposal.

5. Sewage equipment maintenance pressure. After a long period, various types of equipment in poor working conditions under the accumulation of wear and tear will lead to various types of failure. At the same time, the number and composition of the water are constantly changing. It is necessary to adjust the parameters of the sewage treatment equipment and drug delivery dynamically, and timely monitor the biochemical reaction quality. These will result in the equipment facing a lot of routine maintenance work.

\section{Multi-mode AO + MBR process}

The multi-mode $\mathrm{AO}+\mathrm{MBR}$ process performs a function of degradation resistance, but bioreactors alone or membrane filtration alone cannot perform. Organic pollutants and suspended solids have a certain treatment effect. The conventional process of sludge separation is achieved by sedimentation tank, while the multi-mode AO + MBR process applies membrane separation technology. It replaces the conventional activated sludge process with secondary sedimentation tanks and deep treatment processes, and has the effect of removing the microorganisms on which the biological treatment process depends on the biological treatment process. The separation of the microorganisms from the culture medium (mixture) allows the microorganisms to be retained in the biochemical reaction tank, while ensuring that the effluent contains fewer microorganisms and other suspended solids. The multi-mode AO + MBR process is characterized by a complete separation of hydraulic retention time and sludge age in the bioreactor. The high sludge age with low residence time allows for a better and richer microbial population in the sludge, which not only increases the ability of resisting shock loads but also more stable effluent. The process provides an opportunity for organic pollutants, nitrogen and other pollutants to be discharged. The degradation of contaminants creates favorable conditions.

The multi-mode $\mathrm{AO}+\mathrm{MBR}$ process is characterized by the immersion of a dedicated membrane module in a mixed solution, either pumped by an integrated membrane pump. Driven by the different water level, the water (through the microporous membrane) is drained out of the biochemical reaction cell, where microorganisms, cells and other particles are intercepted within the biochemical reaction cell. The most important feature of the submerged MBR is the exceptionally low operating pressure with transmembrane resistance typically not exceeding $50 \mathrm{kPa}$. The process adopts low differential pressure and permeate flux, which has weak differential polarization on the membrane surface and can be achieved by applying certain perturbations on the membrane surface. It is common practice to inflate the membrane surface, thereby subjecting it to violent perturbations of the gas-liquid phases to retard this process effectively.

The multi-mode $\mathrm{AO}+\mathrm{MBR}$ process owns the properties of small footprint, high treatment efficiency and stabilities. In the multi-mode AO + MBR process, the shortcomings of unstable water quality and easy expansion of the sludge in traditional process can be overcome by replacing the conventional activated sludge process with a membrane module instead of a secondary clarifier.

(1) High quality produced water flow 
After being treated with membrane bioreactor technology, the wastewater in general (where domestic wastewater accounts for a large proportion) has a COD up to $30 \mathrm{mg} / \mathrm{L}$, BOD up to $5 \mathrm{mg} / \mathrm{L}$, the content of $\mathrm{NH}_{3}-\mathrm{N}$ near to 0 . It can be directly recycled for cooling circulating water, domestic miscellaneous water and other fields, which is generally difficult to achieve in traditional processes. This high-quality water can be directly reused and may effectively reduce the subsequent treatment process and lower investment or operating costs.

All the activated sludge in the tank can be intercepted by the membrane separation (membrane pore size of $0.1 \mu \mathrm{m})$. The biological co-metabolism is achieved, thus greatly increasing the removal rate of indestructible organic matter. The separation of mud age and hydraulic retention time is limited (Feng et al. 2021). As a result, nitrifying bacteria with a long generation cycle can be effectively multiplied, which greatly increases the concentration of $\mathrm{NH}_{3}-\mathrm{N}$ in wastewater and obtain clear and high-quality reuse water. The turbidity of the effluent after treating by the membrane bioreactor can reach below 0.1 NTU and SDI value less than $3 \%$. It can be used directly as feed water for sodium filtration or reverse osmosis, which provides the possibility for wastewater resource utilization and economic sustainability.

\section{(2) Strong impact load resistance}

Due to the high concentration of activated sludge in the membrane bioreactor, which is two to five times that of the traditional process, the microbial population is rich and the biological chain is complete, so it has a strong ability to resist impact loading.

As a result of membrane separation, the sludge age and hydraulic retention time can be separated. Besides, the sludge concentration can be artificially controlled according to the change of water quality and water quantity, and then, the control of volumetric load can ensure stable water quality.

\section{(3) Easy expansion of processing capacity}

As the membrane separation technology has strong modular characteristics, it has the characteristic of easy amplification and very convenient capacity expansion. The treatment capacity can be very convenient to achieve by increasing the discharge membrane unit and sludge concentration in the biological treatment building.

\section{(4) Low amount of residual sludge}

It can effectively reduce the cost of subsequent sludge disposal and reduce secondary pollution to the environment.
Due to the long age of the mud, the amount of residual sludge produced is low and stable.

(5) High degree of automation and stable control operation.

For any wastewater treatment system, its stable operation is very important. Thus, it is particularly important to improve the level of automation and control to reduce human interference. Intelligent control of the processing system can be achieved by using the necessary online instrumentation and necessary software programs and databases.

\section{Process design scheme}

The wastewater from enterprises in the park is transported to the plant area of the project by special pressure pipes, in which the process of regulating tank + calcium removal tank + nitrification tank is adopted for the treatment of fluorine-containing wastewater, fine grid + aerated grit chamber + membrane grid tank + hydrolysis acidification tank is used for pretreatment; multi-mode AO tank + MBR tank + UV disinfection process is adopted for main wastewater treatment; pretreatment + multi-mode $\mathrm{AO}+\mathrm{MBR}$ is used for main process of the project membrane process; this scheme has the advantages of stable treatment effect, rich operation experience, strong shock load resistance and saving floor area. Moreover, the proportion of industrial wastewater in this project is relatively high. MBR is more suitable for the complex water quality of industrial wastewater (Liu et al. 2021). It can be combined with subsequent treatment units to remove pollutants such as refractory organics. The process flow is shown in Fig. 1.

The main biochemical process of this project is a "multimode $\mathrm{AO}+\mathrm{MBR}$ membrane" process, which is characterized by long residence time (Ji et al. 2021). Most of the nondegradable COD has been removed by aeration with delayed aeration, while the remaining was removed by aerosols.

After the above process treatment, the remaining COD has become more difficult to degrade by using biochemical processes, although the MBR membranes have largely retained insoluble COD.

Advanced oxidation technology (AOT) is now more commonly used in biodegradation of COD, which is the main application form of oxidation and known as deep oxidation technology. AOT was characterized by the generation of hydroxyl radicals $(-\mathrm{OH})$ with strong oxidation capacity under high temperature and pressure, electric, acoustic, optical, and other conditions. Under suitable reaction conditions such as irradiation and catalysts, the oxidation of large molecules in refractory organic matter will be decomposed into small molecules of low or non-toxic substances (Rashid 2020). According to the way of producing free radicals and 


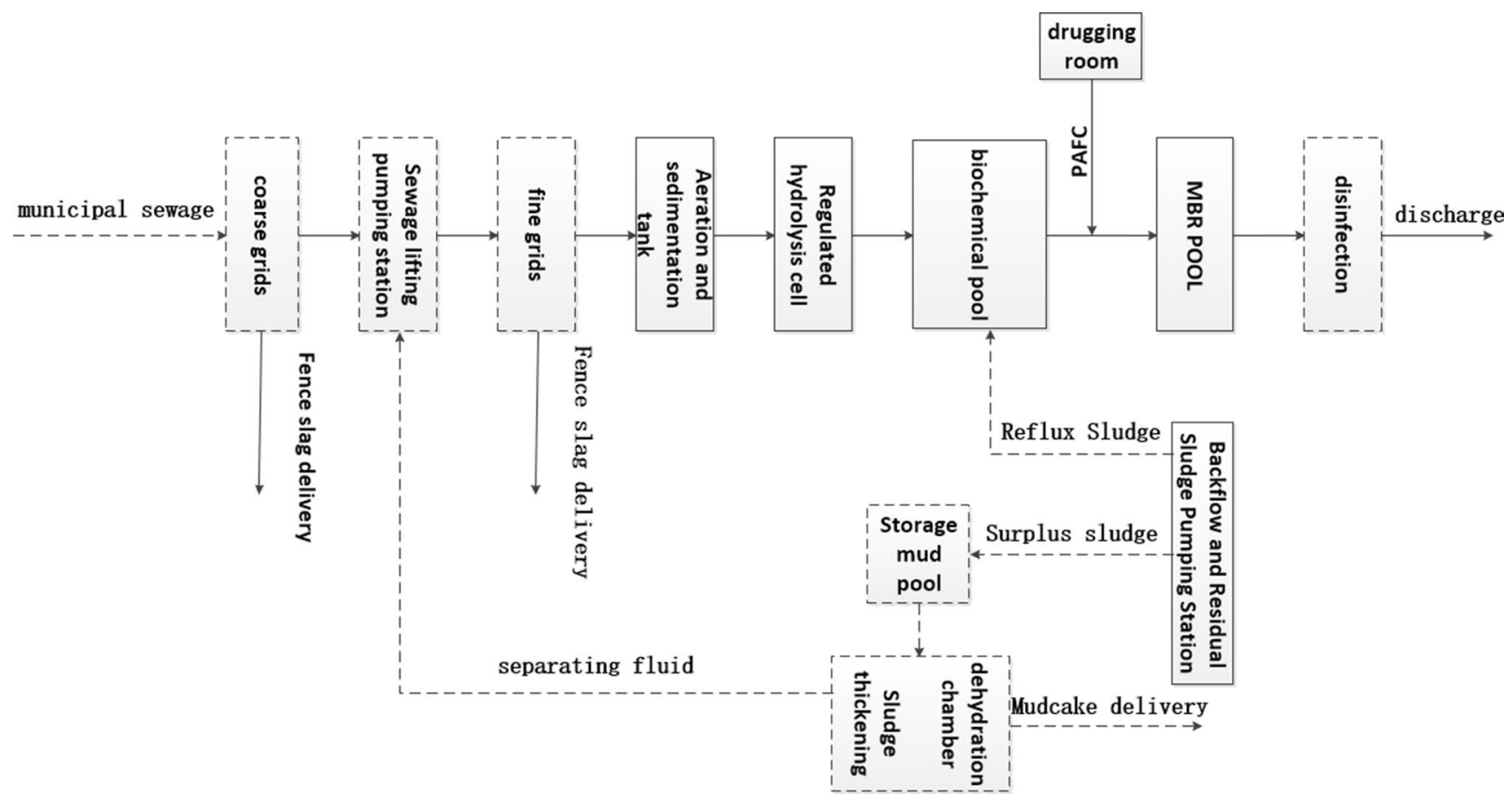

Fig. 1. The flow charts of scheme

reaction conditions, they can be classified as photochemical oxidation, catalytic wet oxidation, acoustic chemical oxidation, ozone oxidation, electrochemical oxidation, Fenton oxidation, etc.

In recent years, with the improvement of wastewater discharge standards, advanced oxidation technology in industrial park wastewater treatment and domestic municipal mixed sewage deep treatment has been widely applied in Tianjin, Hebei, Shandong, Beijing and other places. To provide protection for the effluent $\mathrm{COD}_{\mathrm{Cr}}$ stable standard, the main technology is ozone oxidation and Fenton oxidation.

In this paper, the sewage treatment plant treats industrial waste water from 20 large silicon wafer manufacturing enterprises of the Integrated Circuit Materials Industrial Park of Wuxi. The Industrial sewage is collected from a complete diversion system which is composed of soil pipelines connected manufacturing enterprise's outfalls (Ji et al. 2021). Currently, the main sewage capacity is from Zhonghuan Semiconductor which can produce 750,000 pieces of 8 -inch silicon wafers and 600,000 pieces of 12 -inch silicon wafers every month. The sewage volume of the project has been about 10,000 tons/day in 2019 and will reach 20,800 tons/ day by the end of 2020, and 34,000 tons/day in 2023 .

In another 10GW solar crystalline silicon chip slicing factory, the current maximum amount of sewage is 3,341 tons/day. And there will be some new industries entering the industrial park in the future, so it is difficult to predict accurately. Therefore, in the near future (2022), 10\% of the total sewage volume will be considered and $30 \%$ of the total sewage volume will be considered in the long term. Therefore, the total planning scale of sewage treatment plant can be determined as 50,000 tons / day.

\section{IoT system design solutions}

Comprehensive China's water treatment plants are scattered and small. In addition, the water quality is different. They also have the disadvantages of weak investment, resource dispersion, backward management and technical personnel and lack of professional guidance.

The application of IoT can monitor various types of sewage treatment equipment network, which are attached in the whole process of the automatic control system, the city's sewage treatment nodes, production and sewage in the running state. Online control of pipe valves by IoT control nodes can also solve the shortcomings in the existing sewage treatment model. The establishment of the wastewater treatment system based on the IoT system can achieve real-time control of treatment production of all kinds of resources by preset configurations (Su et al. 2020), and it also can further enhance the crisis operational response speed, standardized management, energy saving and economic efficiency.

Overall system framework has a top principle that the wastewater treatment needs to maintain 24-h continuous operation (Liu et al. 2014), and the sensor deployment method must ensure sufficient integrity mechanisms to

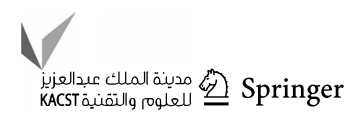


protect stable operation of the wastewater treatment process from guaranteeing disasters in $7 \times 24 \mathrm{~h}$.

The topological ring bus and edge computing can be used to realize centralized management, decentralized control and timely response of the system. An online supervision system for sewage treatment based on the IoT that monitors the real-time status of sewage treatment equipment, depending on the definition of the implementation function, can also schedule management resources in real time. It is defined as four composition modules: the sensory, network, data and business layers (Drenoyanis et al. 2019).

The sensory layer is mainly composed of water quality monitoring and flow control IOT sensors (Somov et al. 2018), which realize basic function control and strategy configuration through on-site intelligent gateway, water quality collection, flow rate and valve status at regular and frequent intervals. The sensory can execute switch and restart command.

The network layer consists of a data transmission bus such as Zigbee and a GPRS remote data transmission network (Liu et al. 2010), which is responsible for the transmission of wastewater treatment data to the central server.

The data layer is responsible for receiving and processing the sensor monitoring data transmitted from the field IOT devices (Xiu et al. 2019). Its function definition is preliminarily filtered and pre-processed to the real-time collected data according to the device preset business thresholds and intelligent supervisory strategies. It also forms a number of different data modules such as device online status, device real-time parameters, device history status, device real-time alarms, device history alarms, and so on.

The business layer is mainly responsible for the data layer which is filtered to meet the business definition of the data to achieve supervision and circulation (Jacob and Pravin 2018). While an alarm occurs, a wastewater treatment task will be produced. After verification by business indicators, the platform will push the duty officer or supervisor audit a formation of regulatory tasks or operational requirements (Saharuddin et al. 2019). The duty node operators fill in a task form which has duty information to the task distribution center with the feedback results on time (Fig. 2).

The main functions of the system should be able to realize the wastewater IOT data collection, remote control of water quality after treatment, operation state supervision for equipment, maintenance staff scheduling, the wastewater treatment node communication, task work order flow, monitoring data management center, wastewater treatment IOT equipment center and other core contents (Asthana et al. 2019).

Sewage IOT data acquisition module (SIDAM) is compatible with all kinds of IOT monitoring device middleware for state data acquisition, and responsible for establishing a conversion channel to obtain several kinds of data collection and device control. In this sense, IOT data module can abstract different IOT devices from different models and types (Rezwan et al. 2019), according to the equipment asset number of the sewage treatment IOT device center. The module can identify the type of different devices in the perception layer and select a suitable data reading interface according to the device ID number.

The wastewater IOT data collection module (WICOM) can be used to pre-clean (Mangayarkarasi et al. 2019), control and pre-process the real-time IOT device data collected from the sensing layer, which is according to pre-processing intelligence policies and based on the device's operational status supervision.

Remote control of water quality treatment (RECWAT): Remote control of water quality treatment equipment in the wastewater treatment process, such as various types of valves, roots fan, ultraviolet disinfection, drug delivery and other key control node (Murugaanandam et al. 2018),
Fig. 2. Internet of Things system structure diagram
Sewage disposal system
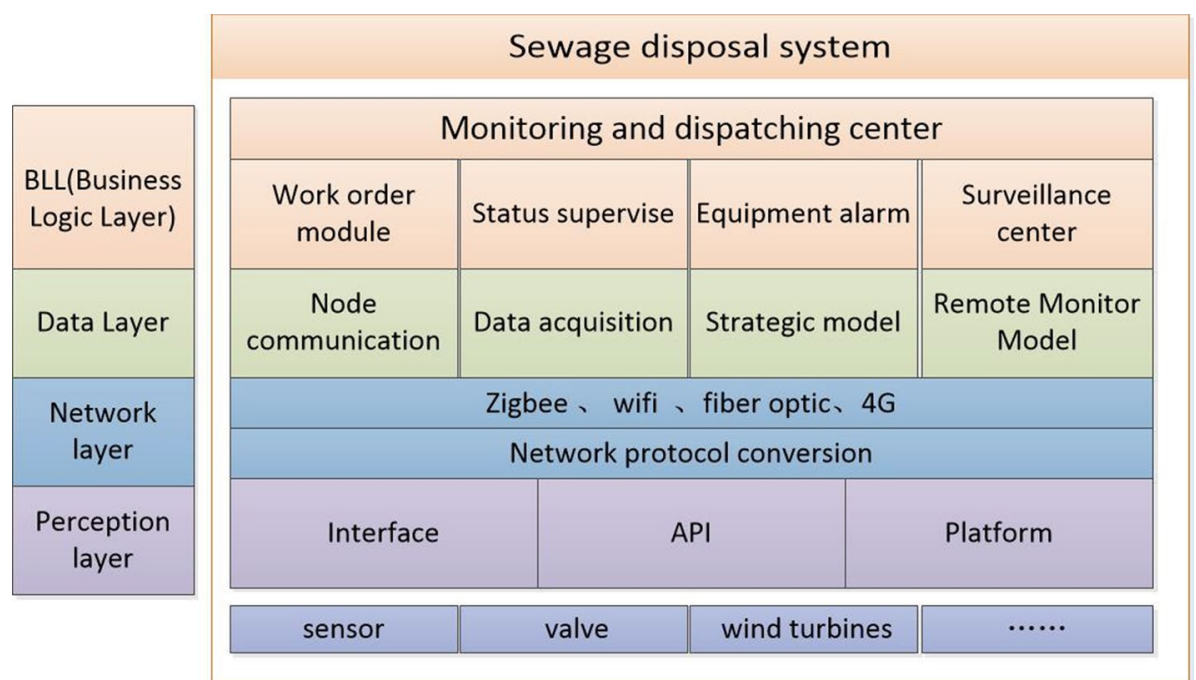
can be adjusted according to the equipment operating state supervision of preset parameters, dynamic monitoring of water indicators. The implementation of preset strategies also can be applied under the quality control of wastewater treatment as well.

Equipment operational status monitoring (EQOSM) The multi-mode for $\mathrm{AO}+\mathrm{MBR}$ membrane process is an economically efficient process for wastewater treatment, which is more suitable for toxic and harmful industrial wastewater treatment (Ji et al. 2021). This technology has good application results in some area projects, and high real-time monitoring requirements for key control indicators such as nitrogen, phosphorus, oxygen, microorganisms and transmembrane resistance. In the operation plant, the water data about the composition and volume need to be updated as quickly as possible according to the season, off-peak season, weather and other factors (Cheng et al. 2021; Davila et al. 2021; Feng et al. 2021; Galintin et al. 2021; Ji et al. 2021; Rashid 2020). The ability to preset the relevant control threshold and the specific associated strategy is also needed, in order to achieve a timely adjustment of the wastewater treatment process under different combinations of monitoring indicators. After the system detection indicator triggers a preset threshold and associated policy action, an alarm message and preset action execution ledger are formed.

Maintenance personnel dispatching (MAPDIS) According to the detection alarms, the system pushes the execution draft task table to the supervisors in the duty center based on the equipment operation status supervision module. The MAPDIS can dynamically track the current location of the operators on-duty in the duty center where the center supervisors can adjust whole task work orders in wastewater treatment according to task scheduling information such as work type, location and ownership.

Nodes communication (NoCom) In the area of this study, 10 sewerage systems are currently in operation and another 17 sewerage systems are planned for construction. There are already two wastewater treatment plants with current sizes of $75,000 \mathrm{~m}^{3} / \mathrm{d}$ and $50,000 \mathrm{~m}^{3} / \mathrm{d}$, respectively. Another one is under construction with a planned treatment capacity of 50,000 tons per day. The above-mentioned nodes will form a complete sewage treatment system including the collection, transportation, treatment and discharge of rainwater, domestic sewage and industrial wastewater from urban roads. The NoCom can collect real-time data flow from each sewage treatment nodes and timely report summary of water quality parameters and sewage treatment process, as well as real-time interaction of monitoring parameters. They can also control water input/output capacity online, and correct various types of drug dosage according to sewage treatment quantity dynamically.

Task Work Order Distribution (TaWoD) It serves the distribution of tasks under execution and can realize the dynamic configuration of task distribution order nodes. It has management of equipment maintenance operation tasks, wastewater treatment operations, emergency event alarms, parameter supervision and meter reading, daily equipment inspection, etc. It can be defined, generated and executed according to the service needs dynamically.

Monitoring data management center (MoDaMaC) As the central hub of the wastewater treatment IoT monitoring system, the MoDaMaC platform includes four subsystems: they are data receiving which can monitor IoT equipment (Soprani et al. 2018), equipment log and alarm ledger, business work order, data statistical analysis and mobile task distribution. Each part collaborates to analyze and process the received data which are stored later. Data receiving subsystem is responsible for real-time data collection of various field sensors and devices (Liu et al. 2018). Equipment log and alarm ledger can record water quality monitoring and equipment operation log data in a running database. Using the alarm ledgers, it can send out SMS and mobile alarm messages to the duty officer. The data statistical analysis subsystem provides various types of data statistical forms to managers, formation of task work orders, statistical task disposal rate, equipment failure rate, water quality qualified rate, and water quality changes also can be in the report analysis operation. The mobile task distribution can release the dynamic quality data of wastewater treatment to the staff on duty at each node, and can track the trajectory of the mission.

Wastewater treatment IoT equipment center (IotCenter) Wastewater treatment environmental conditions are generally harsh, which is more serious in equipment and sensors wear (Girisrinivaas et al. 2017; Liu et al. 2014). Frequent maintenance and turnover of equipments have many adverse effects on the continued operation of wastewater treatment lines (Guo et al. 2019; Murugaanandam et al. 2018). The IotCenter will enable the rapid and dynamic replacement of wastewater IOTW assets (Carrasquilla-Batista et al. 2017; Mangayarkarasi et al. 2019), which will significantly shorten the commissioning cycle for re-entry after equipment replacement. The IotCenter will form a list of equipment assets according to the whole system which can help other modules to optimize equipment maintenance schedule and alert abnormal faults from various types of assets.

\section{Innovation points}

1) The concepts about integration of IoT monitoring into wastewater treatment business processes.

In the study, the application of IoT system upgrades the automation and production control mode of the traditional configuration framework to collect the status and control 
information from the key nodes in the whole wastewater treatment process (Jacob and Pravin 2018; Murugaanandam et al. 2018; Samtani et al. 2016). Based on the wastewater collection nodes (Iyer and Giri 2020; Rezwan et al. 2019), equipment operation and maintenance status and wastewater plant environmental parameters, are collected to establish a comprehensive state of wastewater disposal factors, including the formation healthiness of wastewater treatment in quantification of the wastewater treatment process quality.

2) Establishment of mission management mechanisms to integrate personnel and specific operations (Guo et al. 2019; Mangayarkarasi et al. 2019).

The model establishes a framework which has routine inspection, routine maintenance, equipment failure repair, task results review and staff single assessment for the sewage treatment line security system. It can integrate the sewage treatment line operators between specific sewage process and equipment closely. As a result, a business interaction mechanism between personnel and the wastewater system is established to achieve a more efficient interaction mechanism among personnel operations and decision making, wastewater treatment line equipment, wastewater collection and treatment and discharge in the urban wastewater treatment process.

3) Formation of an online cloud platform for continuous testing of sewage treatment operations.

The establishment about a set of real-time online sewage disposal business cloud platform will involve the state of sewage disposal inspection (Drenoyanis et al. 2019), abnormal alarms, water quality monitoring, collection of tube wells, supplies put, maintenance control, personnel scheduling and other key business information, to achieve centralized operation and maintenance management. And it can further establish a set of wastewater disposal operation and maintenance big data monitoring system, which further study atmospheric precipitation, high crystal silicon wafer seasonal capacity adjustment, seasonal domestic wastewater and other factors, and wastewater treatment business with the connotation of correlation between the business, to achieve a further allocation of equipment, consumables, personnel, maintenance and other resources.

\section{Case studies}

In this study, the case is a wastewater treatment project in the economic development zone in Wuxi. The main industrial wastewater comes from the large semiconductor wafer manufacturers in the integrated circuit materials industrial

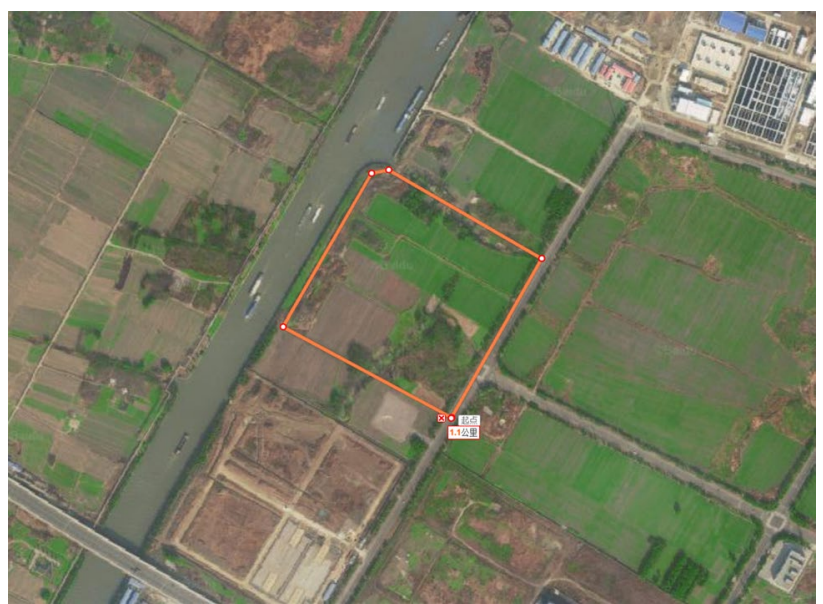

Fig. 3. Sewage treatment project site

park. The production of semiconductor chemical material supply-crystalline silicon wafer-polished wafer-epitaxial wafer-chip manufacturing, packaging test and other business processes will produce a large number of toxic and harmful industrial wastewater. According to the requirements of regulations such as the Regulations on the Prevention and Control of Water Pollution in Taihu Lake, Jiangsu Province, the emission targets for COD, ammonia nitrogen, total nitrogen, total phosphorus and other water pollutants are strictly limited (Fig. 3).

The total effluent volume of each enterprise is estimated to be 50,400 tpd in 2023, and the tailwater discharge will be connected through the tailwater discharge pipe to the Burning Point Canal. According to the Water System Plan, the flood level of a discharging water body is $5.22 \mathrm{~m}$ for a 20 -year event, $5.37 \mathrm{~m}$ for a 50 -year event and $5.65 \mathrm{~m}$ for a 100-year event. The main wastewater discharged by major silicon wafer manufacturers in the region includes: (1) domestic sewage (taken over directly); (2) production wastewater (treated by the "physicochemical + biochemical" treatment system); (3) sand-containing and primary rinsing water (coagulation, air flotation, filtration and other physicochemical treatment).

Industrial wastewater mainly includes fluorine wastewater, ammonia wastewater, alkali wastewater and sand wastewater. The fluoride wastewater is treated by homogenizing and adjusting the wastewater and adding excess calcium ions to coagulate and precipitate to produce calcium fluoride. The effluent standard is limited at $10 \mathrm{mg} / \mathrm{L}$ by the discharge standard of pollutants for municipal wastewater treatment plant and emission standard of pollutants from electronic industry. There will be about $704 \mathrm{t} / \mathrm{d}$ fluoride wastewater after the completion of Phase I and $1581 \mathrm{t} / \mathrm{d}$ after the completion of Phase II. The ammonia-containing wastewater is treated by adjusting the $\mathrm{pH}$ value and then nitrifying in the 
AO biochemical tank. The ammonia nitrogen index of the effluent is less than $20 \mathrm{mg} / \mathrm{L}$. The acid-base wastewater is adjusted to 6-8 through neutralization and homogenization.

The project is an urban wastewater treatment plant (accepting industrial wastewater) locating in the secondary protection area of Taihu Lake. According to Table 1 standard and relevant regulations in the "Emission Limit Values of Major Water Pollutants from Urban Wastewater Treatment Plants and Key Industries in Taihu Lake Region" (DB32/1072-2018) (Table 2), the main pollutants in the effluent quality should meet the requirements in the following Table 3.

In this study, the multi-mode $\mathrm{AO}+\mathrm{MBR}$ process was chosen to treat the wastewater from the large silicon wafer industry as the main component. The process has two processes to achieve $90 \%$ denitrification efficiency. It plays a key function that a separate bioreactor or a separate membrane filtration has a certain effect on the treatment of undegradable organic pollutants and suspended solids. The multi-mode $\mathrm{AO}+\mathrm{MBR}$ process has the properties of small footprint, good treatment efficiency and stable sludge. In the multi-mode $\mathrm{AO}+\mathrm{MBR}$ process, instead of the secondary sedimentation tank in the traditional activated sludge process, membrane modules are used for efficient solid-liquid separation which can overcome the shortcomings of the traditional process such as unstable effluent quality and sludge expansion.
Table 2 Total sewage of each enterprise

\begin{tabular}{llll}
\hline Serial number & Enterprise & $\begin{array}{l}\text { Sewage volume in } \\
\text { 2020 (Tons/day) }\end{array}$ & $\begin{array}{l}\text { Sewage volume } \\
\text { in 2023 (Tons/ } \\
\text { day) }\end{array}$ \\
\hline 1 & A & 20832 & 33998 \\
2 & B & 3341 & 3341 \\
3 & C & 1350 & 1350 \\
4 & D & 63.9 & 63.9 \\
5 & E & 2558.69 & 11625 \\
Total & & 28145.59 & 50378.77 \\
\hline
\end{tabular}

\section{Effectiveness of system operation}

The stable operation of its process is very important. The use of IOT monitoring system to minimize the disturbance caused by manual meter reading, feeding and control can significantly improve the level of automation control, reduce the human overhaul and interference brought about by operational factors. This study defines the IOT sewage treatment system module, which will realize the automation of the wastewater plant production process, human resources, equipment and instrumentation, procurement inventory and other production factors of information. The plant production scheduling, administrative office, logistics management, production environment monitoring network and visualization are included also. Above design point fits

Table 1 Statistics of sewage volume

\begin{tabular}{|c|c|c|c|c|c|c|}
\hline Stage & Time & $\begin{array}{l}\text { 8-Inch product } \\
\text { Sewage volume } \\
\text { tonne /d }\end{array}$ & $\begin{array}{l}\text { 12-Inch product } \\
\text { Sewage volume } \\
\text { tonne /d }\end{array}$ & $\begin{array}{l}\text { Power effluent } \\
\text { quantity } \\
\text { Sewage volume } \\
\text { tonne /d }\end{array}$ & $\begin{array}{l}\text { Domestic sewage } \\
\text { volume } \\
\text { Sewage volume } \\
\text { tonne /d }\end{array}$ & $\begin{array}{l}\text { Total } \\
\text { tonne /d }\end{array}$ \\
\hline Power equipment commissioning & 2018.11 & & & 1576 & 89 & 1665 \\
\hline \multirow{3}{*}{$\begin{array}{l}\text { Part of the production equipment com- } \\
\text { missioning }\end{array}$} & 2018.12 & 1079 & & 291 & 89 & 1459 \\
\hline & 2019.01 & 2541 & & 476 & 142 & 3159 \\
\hline & 2019.07 & 5461 & 1500 & 1728 & 142 & 8831 \\
\hline $\begin{array}{l}8 \text {-inch } 500,000 \\
12 \text {-inch } 150,000\end{array}$ & 2020.01 & 6234 & 3508 & 2219 & 178 & 12139 \\
\hline $\begin{array}{l}8 \text {-inch } 750,000 \\
12 \text {-inch } 150,000\end{array}$ & 2020.07 & 9529 & 3508 & 3101 & 267 & 16405 \\
\hline $\begin{array}{l}8 \text {-inch } 750,000 \\
12 \text {-inch } 300,000\end{array}$ & 2021.01 & 9529 & 7016 & 4020 & 267 & 20832 \\
\hline $\begin{array}{l}\text { 8-inch } 900,000 \\
12 \text {-inch } 300,000\end{array}$ & 2021.07 & 12863 & 7016 & 4908 & 267 & 25054 \\
\hline $\begin{array}{l}8 \text {-inch } 900,000 \\
12 \text {-inch } 450,000\end{array}$ & 2022.01 & 12863 & 10524 & 5827 & 356 & 29570 \\
\hline $\begin{array}{l}8 \text {-inch } 900,000 \\
12 \text {-inch } 450,000\end{array}$ & 2022.07 & 12863 & 10524 & 5827 & 356 & 29570 \\
\hline $\begin{array}{l}8 \text {-inch } 900,000 \\
12 \text {-inch } 600,000\end{array}$ & 2023.1 & 12863 & 14033 & 6746 & 356 & 33998 \\
\hline
\end{tabular}


Table 3 Main pollutants of effluent water quality

\begin{tabular}{llllllll}
\hline Pollutant name & $\begin{array}{l}\text { chemical oxygen } \\
\text { demand }\left(\mathrm{COD}_{\mathrm{Cr}}\right)\end{array}$ & $\begin{array}{l}\text { biochemical } \\
\text { oxygen demand } \\
(\mathrm{BOD})\end{array}$ & $\begin{array}{l}(\mathrm{SS}) \\
\text { suspension }\end{array}$ & $\begin{array}{l}\left(\mathrm{NH}_{3}-\mathrm{N}\right) \\
\text { ammonia nitro- } \\
\text { gen }\end{array}$ & $\begin{array}{l}\text { (TN)total nitro- } \\
\text { gen }\end{array}$ & $\begin{array}{l}\text { (TP) } \\
\text { total phosphorus }\end{array}$ & $\begin{array}{l}\text { Fluoride emission } \\
\text { limit values }\end{array}$ \\
\hline$(\mathrm{mg} / \mathrm{L})$ & 40 & 6 & 10 & $3(5)$ & $10(12)$ & 0.3 & 1.5 \\
\hline
\end{tabular}

(1) The value outside the bracket is the control indicator when the water $\mathrm{T}$ is $>12^{\circ} \mathrm{C}$, and the value inside the bracket is the control indicator when the water $\mathrm{T}$ is $\leq 12{ }^{\circ} \mathrm{C}$

(2) The standard in reeling, hemp spinning, inorganic chemicals, phosphate fertilizer, sulfuric acid, paper industry wastewater when $\mathrm{T} \leq 12 \mathrm{o} \mathrm{C}$ $\mathrm{TN}$ is still according to $10 \mathrm{mg} / \mathrm{L}$

the current requirements from Chinese government departments. Economic sectors needs to build up the e-government and e-commerce which accelerate the construction of the wastewater plant into a highly automated and information technology level as convenient management of modern sewage treatment enterprises.

(1) Follow "decentralized control, centralized management". According to the requirements of the production process and the process function, the model can fit in with all the needs of the process function for detection and control site settings. To ensure the operation stability and reliability of all parts of the system after the failure from one of them, the whole system performance is optimized for the service of process production. The platform has a design concept which is "centralized monitoring and management, decentralized control", and it can ensure the operational efficiency of the entire wastewater treatment plant.

(2) Meet the automated control. The platform can achieve management of wastewater treatment plant production, wastewater treatment process, and the automated control in the configuration of the integrity and adaptability. The principle of integration should choose efficient integrated equipment, which is easy to control, management and maintenance. The principle of modularization, commercialized, generalized and modular structured equipment should be used in both software and hardware, so that the system has strong expansion capability.

(3) According to the requirements of the process and the characteristics of the equipment, control stations and network are set up. Three levels of control should be achieved: first, the field at the machine manual control; second, the local control station unit centralized automatic control; third, centralized control of the central control room plant-wide control.

(4) The hardware configuration should be in line with international industrial standards with high reliability, strong adaptability, flexible expansion, easy operation and maintenance. It should also be configured with an open architecture, good human-machine interface, complete system platform software. Management and monitoring software is developed from the perspective of ease of management and optimal control. The potential in redevelopment by the user is also considered. The supplier of the equipment is able to provide longterm technical support and service, while spare parts are guaranteed.

(5) Higher system cost performance. The design of the system takes into account production, management, safety, economy and other factors. The process and related equipment are integrated into the system. Considering the selection of equipment, the selection of well-known professional manufacturers with rich experience, the ability as the supply wastewater plant products supplier, can improve the reliability of sewage treatment significantly. On this basis, while considering the investment of the construction side, the system can achieve advanced technology, reliable performance and reasonably costs.

\section{Conclusion}

After the sewage treatment plant is completed and put into operation, a large amount of pollutants can be intercepted every year. Furthermore, the treated tail water can be used as water supply source for road landscape. Obviously, the project has a significant effect on improving regional water environment quality, and its environmental benefits are huge. The estimated pollutants can be reduced each year as follows (Table 4):

The indirect economic benefits of the project are mainly reflected by reducing the economic losses caused by water pollution to the society. It can reduce the investment and running cost to the enterprises in the park obviously while compare to decentralized sewage treatment method. The sewage contains nutrients such as $\mathrm{BOD}_{5}, \mathrm{~N}, \mathrm{P}$ and $\mathrm{K}$, which can be transformed into mud cake after sewage treatment, and they can be used as garden fertilizer. While the plant is finished, the water quality of Taihu Lake will be significantly improved also. 
Table 4 System inlet and outlet water quality $(\mathrm{mg} / \mathrm{L})$

\begin{tabular}{llllllll}
\hline Project & BOD5 & CODCr & SS & TN & $\mathrm{NH}_{3}-\mathrm{N}$ & TP & Thloride \\
\hline Inflow water & 180 & 350 & 300 & 55 & 40 & 4.5 & 10 \\
Designed effluent & $\leq 6$ & $\leq 40$ & $\leq 10$ & $\leq 10$ & $\leq 5$ & $\leq 0.3$ & $\leq 1.5$ \\
\hline
\end{tabular}

Acknowledgements This work was supported by National Key Research and Development Project of China (2017YFB0403504).

Funding The author(s) received no specific funding for this work.

\section{Compliance with ethical standards}

Conflict of interest The authors declared that we have no conflict of interest.

Open Access This article is licensed under a Creative Commons Attribution 4.0 International License, which permits use, sharing, adaptation, distribution and reproduction in any medium or format, as long as you give appropriate credit to the original author(s) and the source, provide a link to the Creative Commons licence, and indicate if changes were made. The images or other third party material in this article are included in the article's Creative Commons licence, unless indicated otherwise in a credit line to the material. If material is not included in the article's Creative Commons licence and your intended use is not permitted by statutory regulation or exceeds the permitted use, you will need to obtain permission directly from the copyright holder. To view a copy of this licence, visit http://creativecommons.org/licenses/by/4.0/.

\section{References}

Al-Bayari O, Sadoun B, Shatnawi N (2020) An Internet and wireless networking-based water pipes web application for fault reporting. Int J Commun Syst 33:12. https://doi.org/10.1002/dac.4363

Asthana N, Bahl R, IEEE (2019) IoT device for sewage gas monitoring and alert system. In: Proceedings of 2019 1st international conference on innovations in information and communication technology. IEEE, New York

Belkada FD et al (2018) Electrodialysis for fluoride and nitrate removal from synthesized photovoltaic industry wastewater. Sep Purif Technol 204:108-115. https://doi.org/10.1016/j.seppu r.2018.04.068

Carrasquilla-Batista A, Chacon-Rodriguez A, Murillo-Vega F, Nunez-Montero K, Gomez-Espinoza O, Guerrero-Barrantes M (2017) Characterization of biomass pellets from Chlorella vulgaris microalgal production using industrial wastewater. In: 2017 international conference in energy and sustainability in small developing economies

Cheng BY, Wang Y, Hua YM, Heal KV (2021) The performance of nitrate-reducing $\mathrm{Fe}(\mathrm{II})$ oxidation processes under variable initial
Fe/N ratios: The fate of nitrogen and iron species. Front Environ Sci Eng 15:12. https://doi.org/10.1007/s11783-020-1366-2

Davila J, Sulbaran M, Pena-Vera M, Perez-Perez E, Nelson V (2021) Biological activity of black liquor, lignin and vinasse. Ciencia E Ingenieria 42:11-21

dos Santos AJ, Sires I, Brillas E (2021) Removal of bisphenol A from acidic sulfate medium and urban wastewater using persulfate activated with electroregenerated $\mathrm{Fe} 2+$. Chemosphere 263:11. https://doi.org/10.1016/j.chemosphere.2020.128271

Drenoyanis A, Raad R, Wady I, Krogh C (2019) Implementation of an IoT based radar sensor network for wastewater. Manag Sens 19:31. https://doi.org/10.3390/s19020254

Feng HR, Liu M, Zeng W, Chen Y (2021) Optimization of the O-3/ $\mathrm{H} 2 \mathrm{O} 2$ process with response surface methodology for pretreatment of mother liquor of gas field wastewater. Front Environ Sci Eng 15:13. https://doi.org/10.1007/s11783-020-1371-5

Galintin O, Rasit N, Hamzah S (2021) Production and characterization of eco enzyme produced from fruit and vegetable wastes and its influence on the aquaculture sludge biointerface research in applied. Chemistry 11:10205-10214. https://doi. org/10.33263/briac113.1020510214

Girisrinivaas R, Parthipan V, Ieee (2017) Drainage overflow monitoring system using IoT (DOMS). In: 2017 IEEE international conference on power, control, signals and instrumentation engineering.

Guo ZY, Sun YJ, Pan SY, Chiang PC (2019) Integration of green energy and advanced energy-efficient technologies for municipal wastewater treatment plants. Int J Environ Res Public Health. https://doi.org/10.3390/ijerph16071282

Huang X, Xiao K, Shen YX (2010) Recent advances in membrane bioreactor technology for wastewater treatment in China. Front Environ Sci Eng China 4:245-271. https://doi.org/10.1007/s1178 3-010-0240-Z

Iyer LS, Giri SV (2020) Harnessing technology for mitigating water woes in the city of Bengaluru. In: George A, Pandian AS, Ayshwarya B, Stephen R (eds) Third national conference on computational intelligence, vol 1427. J Phys Conf Ser. Iop Publishing Ltd, Bristol. https://doi.org/10.1088/1742-6596/1427/1/012004

Jacob TP, Pravin A (2018) Environmental pollution alerting system using IOT research. J Pharm Biol Chem Sc 9:403-406

Ji MZ, Liu ZC, Sun KL, Li ZF, Fan XY, Li Q (2021) Bacteriophages in water pollution control: advantages and limitations . Front 15:15. https://doi.org/10.1007/s11783-020-1378-y

Kao YS, Nawata K, Huang CY (2019) Evaluating the performance of systemic innovation problems of the IoT in manufacturing industries by novel MCDM methods. Sustainability 11:33. https://doi. org/10.3390/su11184970

Liu YS, Du F, Yuan L, Zeng H, Kong SF (2010) Production of lightweight ceramisite from iron ore tailings and its performance 
investigation in a biological aerated filter (BAF) reactor. J Hazardous Mater 178:999-1006. https://doi.org/10.1016/j.jhazm at.2010.02.038

Liu XS, Su XM, Tian SJ, Li Y, Yuan RF (2021) Mechanisms for simultaneous ozonation of sulfamethoxazole and natural organic matters in secondary effluent from sewage treatment plant . Front Environ Sci Eng 15:12. https://doi.org/10.1007/s1178 3-020-1368-0

Liu YZ, Zhang WT, Cui XM, Zhang GD, Wang GX, IEEE (2014) City pipe network intelligent service based on GIS and Internet of Things. In: 2014 7th international conference on intelligent computation technology and automation. https://doi.org/10.1109/ icicta.2014.225

Liu Z et al. (2018) A case study of service-centric IoT model for rural sewage disposal. In: 2018 IEEE 15th international conference on e-business engineering. https://doi.org/10.1109/icebe.2018.00029

Malhotra R, McLeod E, Alzahawi T (2021) Management and maintenance of electrical equipment in industrial facilities. IEEE Ind Appl Mag 27:48-54. https://doi.org/10.1109/mias.2020.3024486

Mangayarkarasi N, Raghuraman G, Kavitha S, IEEE (2019) Influence of computer vision and IoT for pipeline inspection-a review. In: 2019 second international conference on computational intelligence in data science. IEEE, New York

Martinez R, Vela N, El Aatik A, Murray E, Roche P, Navarro JM (2020) On the use of an IoT integrated system for water quality monitoring and management in wastewater treatment plants. Water 12:21. https://doi.org/10.3390/w12041096

Meng SJ et al (2021) Transparent exopolymer particles (TEPs)-associated protobiofilm: A neglected contributor to biofouling during membrane filtration. Front Environ Sci Eng 15:10. https://doi. org/10.1007/s11783-020-1361-7

Murugaanandam S, Ganapathy V, Balaji R, Ieee (2018) Efficient IOT based smart bin for clean environment. In: Proceedings of the 2018 IEEE international conference on communication and signal processing.

Niaei HA, Rostamizadeh M, Maasumi F, Darabi MJ (2021) Kinetic isotherm, and thermodynamic studies of methylene blue adsorption over metal-doped zeolite nano-adsorbent. Phys Chem Res 9:17-30. https://doi.org/10.22036/pcr.2020.233844.1781

Rashid N (2020) Meeting refinery wastewater challenges through membrane-based biological treatment complemented by an integrated asset sustainability program. Desalination Water Treat 176:18-23. https://doi.org/10.5004/dwt.2020.25489

Rezwan S et al. (2019) A minimalist model of IoT based sensor system for sewage treatment plant monitoring. In: 2019 IEEE 10th annual information technology, electronics and mobile communication conference. IEEE, New York

Saharuddin HI, Rahman TA, Elijah O, Khairodin FN, Ieee (2019) IoT application in river monitoring: methods and challenges. In: Proceedings of the 2019 IEEE International Conference on Signal and Image Processing Applications. IEEE, New York, pp 314-318

Samtani S, Yu S, Zhu HY, Patton M, Chen HC (2016) Identifying SCADA vulnerabilities using passive and active vulnerability assessment techniques. In: IEEE international conference on intelligence and security informatics: cybersecurity and big data.

Somov A et al. (2018) Bacteria to power the smart sensor applications: biofuel cell for low-power IoT devices. 2018 IEEE 4th world forum on Internet of Things.

Soprani M et al. (2018) Array of semiconductor nanowires gas sensor for IoT in wastewater management. In: 2018 IEEE international workshop on metrology for industry 4.0 and Iot.

Su JJ, Ding ST, Chung HC (2020) Establishing a smart farm-scale piggery wastewater treatment system with the Internet of Things (IoT) applications. Water 12:13. https://doi.org/10.3390/w1206 1654

Wang ZF, Xu JW, He XQ, Wang YJ (2020) Analysis of spatiotemporal influence patterns of toxic gas monitoring concentrations in an urban drainage network based on IoT and GIS. Pattern Recogn Lett 138:237-246. https://doi.org/10.1016/j.patrec.2020.07.022

Xiu CB, Dong LY, Ieee (2019) Design of sewage treatment monitoring system based on internet of things. In: Proceedings of the 2019 31 st Chinese control and decision conference. chinese control and decision conference. IEEE, New York, pp 960-964

Publisher's Note Springer Nature remains neutral with regard to jurisdictional claims in published maps and institutional affiliations. 